\title{
Devising and validating a headache diary in a series of patients with chronic daily headache from Colombia
}

\author{
Diseño y validación de un diario de cefalea en pacientes con cefalea crónica diaria en \\ Colombia
}

Gabriel F. Torres', Martha I. Otálvaro', Juan C. Vargas², Yulexi Castellanos 3 , Jeimy Xiomara García , Javier D. Triana ${ }^{3}$, Cesar A. Forero ${ }^{3}$, Carlos D. Guevara 4 , Rodrigo Pardo 5

\begin{abstract}
Objective: To devise and test the reliability and validity of a brief headache diary in a series of Colombian patients with chronic daily headache. Methods: The study was designed in five stages: selection of domains (group of patients and experts); initial devising of the items (writing group); identification of non-understandable items ( $n=20)$; assessment of internal consistency ( $n=100)$; assessment of validity and assessment of sensitivity to change during seven consecutive days ( $n=25,175$ observations). Results: Five domains were selected: headache presence, severity and length of pain, analgesics intake, and missing workdays. The headache diary is internally consistent $(\approx 75 \%$ of rotated variance), correlates with the medical interview (Spearman's rho and Kendall's tau over 0.8 for each domain) and it has an adequate and stable sensitivity and specificity ( 82 to $96 \%$ ). Conclusions: This headache diary is a reliable and valid instrument and represents the most important features affecting Colombian patients with chronic daily headache.
\end{abstract}

Key words: Colombia, diagnosis, headache disorders, medical records, reproducibility of results, validation studies.

\section{RESUMEN}

Objetivo: Diseñar y testar la validez y reproducibilidad de un diario de cefalea en una serie de pacientes Colombianos con cefalea crónica diaria. Métodos: El estudio fue diseñado en cinco fases: selección de los dominios (grupo de pacientes y expertos); diseño inicial de los ítems (grupo redactor); identificación de ítems no comprensibles ( $n=20)$; determinación de la consistencia interna ( $n=100)$; determinación de la validez y la sensibilidad al cambio durante siete días consecutivos ( $n=25,175$ observaciones). Resultados: Fueron seleccionados cinco dominios: presencia, severidad y duración del dolor, ingesta de analgésicos y días laborales perdidos. El diario tiene una adecuada consistencia interna ( $\approx 5 \%$ de la varianza), se correlaciona con la entrevista médica (rho de Spearman y tau de Kendall $>0.8$ para cada dominio) y tiene sensibilidad y especificidad estables y satisfactorias (82 a 96\%). Conclusiones: Este diario de cefalea es un instrumento confiable y registra las principales características de las cefaleas en pacientes con cefalea crónica diaria.

Palabras-Clave: Colombia, diagnóstico, cefalea, registros médicos, reproducibilidad de resultados, estudios de validación.

The chronic daily headache (CDH) affects from 4 to $7 \%$ of general population worldwide and it is a common cause of consultation in outpatient clinics ${ }^{1-4}$. Patients with $\mathrm{CDH}$ score worse in physical functioning and general health perceptions of quality of life scales than those with migraine and healthy controls ${ }^{5,6}$. Several factors might affect the internal validity of studies in $\mathrm{CDH}$ patients, among them the lack of reliable measurement instruments.

Lipton et al. defined $\mathrm{CDH}$ as headaches that occur for $\geq 4$ hours a day on $\geq 15$ days a month over three months $s^{7}$. In the next decade,

\footnotetext{
${ }^{1}$ Neurologist at Hospital Santa Clara E.S.E., Bogotá, Colombia;

${ }^{2}$ Neurologist at Hospital El Tunal, E.S.E. and Clinica Carlos Lleras Restrepo, Bogotá, Colombia;

${ }^{3}$ Resident of Clinical Neurology at the Universidad Nacional de Colombia, Bogotá, Colombia;

${ }^{4}$ Neurologist at Clinica Carlos Lleras Restrepo, Bogotá, Colombia;

${ }^{5}$ Neurologist at Clinica Carlos Lleras Restrepo; Assistant Professor at the Unit of Clinical Neurology and Centre for Epidemiological Research at Universidad Nacional de Colombia, Bogotá, Colombia.

Correspondence: Gabriel F. Torres; Departamento de Medicina Interna. E.S.E. Hospital Santa Clara; Carrera 15 No. 1 - 59 Sur, Bogotá - Colombia; E-mail: gftorresa@unal.edu.co

Support: This study was partially funded by the Colombian Association of Neurology (Asociación Colombiana de Neurología).

Conflict of interest: There is no conflict of interest to declare.
}

Received 06 July 2011; Received in final form 16 August 2011; Accepted 24 August 2011 
$20 \%$ of the patients with episodic headaches will develop $\mathrm{CDH}^{8}$. $\mathrm{CDH}$ at baseline, coexisting migraine, not being married and sleeping problems increase the risk of worst prognosis.

Several instruments have been developed to evaluate the burden of headaches in patients with migraine ${ }^{9-13}$. However, an adequately validated instrument to assess the headache frequency in Colombian patients with $\mathrm{CDH}$ has not been determined yet. To assess the main characteristics of headache episodes and their impact on work activities, we devised and tested the reliability and validity of a brief headache diary (HD) in a series of Colombian patients with $\mathrm{CDH}$.

\section{METHODS}

Patients aged 18 years or older that fulfilled the International Headache Society (IHS) criteria for migraine or tension type headache with $\mathrm{CDH}$ were recruited for this study ${ }^{14}$. Patients with history of cognitive deficit, severe visual impairment and inability to telephone contact were excluded. The protocol was approved by the Ethics Committee from Hospital Santa Clara, Universidad Nacional de Colombia and Hospital El Tunal, in Bogotá, Colombia.

\section{Devising the items}

\section{Selection of domains}

Fifteen patients with CDH were individually interviewed on the most important issues that a HD should include (group of patients). Likewise, a group of 12 people composed by neurologists and general practitioners, with experience in headache treatment and diagnosis, were individually contacted and interviewed about the most important issues in a HD (group of experts). The proposed domains were gathered and a group of eight people (writing group) performed the initial drafting, including at least three items for each domain.

\section{Detection of ambiguous or non-understandable items}

Ten patients answered the initial draft and explained with their own words the meaning of each item. No other instruction was given. Items that were not understood by each patient were rewritten by the writing group. This second draft was applied to a new series of ten patients until each one of the items was completely understood.

\section{Internal consistency}

Since this instrument has been designed as a multiple domains instrument, the internal consistency was determined through a factor analysis ${ }^{15}$. To this end, the items devised in the previous section were applied to a different set of 100 patients $^{16}$. Analysis of the main components with a Varimax rotation was applied to this set of data. The factors were selected keeping at least one for each domain. The items with loadings $\geq 0.8$ (or otherwise selected as providing information about quantitative pain characteristics) on each factor were kept in the final version of the HD.

\section{Validity}

Two types of validity were tested: criterion (using the neurologist's interview as a golden standard) and construct (using logic construct of intensity, length of pain and analgesic intake). Sensitivity to change was tested assuming that every patient was initiated on prophylactic drugs or at least the dose of previous medication was adjusted. We formally tested the change in severity and length through the follow-up. Test-retest reliability was not tested because of the high variability of the symptoms across time. To test the criterion validity, a group of 28 patients answered the HD during seven consecutive days. By the end of this period, a phone or a personal contact was made by a neurologist. During this interview, presence, length of pain, severity, analgesics intake, and missing workdays were determined for the previous seven days. To test the construct validity, the relationship between severity of symptoms and analgesics intake and length of pain were formally tested. These analyses were repeated for each of the seven days to evaluate consistency through multiple observations.

\section{Statistical analysis}

To determine the relationship between the data in the HD and the golden standard, Spearman's rank correlation coefficient (Spearman's rho) was used for binary variables and Kendall's rank correlation coefficient (Kendall's tau) was used for the ordinal ones. Confidence intervals were calculated according to Altman and Siegel for Spearman and Kendall correlations, respectively ${ }^{17,18}$. The severity of pain was divided into quartiles. The other variables were dichotomized to improve the power of their correlations. To obtain an overall estimate of sensitivity and specificity, which takes into account the variability between each day of fulfilling the HD, an approach based on Generalized Estimating Equations (GEE) was used. To this end, the proportion of positive answers were determined through them along the positive answers in the golden standard (sensitivity). Likewise, the proportion of negative answers was determined with the negative answers in the golden standard (specificity) ${ }^{19}$.

We explored the effect of the day of fulfilling the HD, age, abuse of analgesics, headache subtype, and site of recruitment over the estimates of sensitivity and specificity. Modifications over $20 \%$ of the univariate estimates were considered significant. To determine the construct validity, multiple binomial logistic regressions were calculated using analgesic intake as a dependent variable and severity and length of pain individually as explanatory variables. To determine sensitivity to change, ANOVA repeated measures were used with severity and length of pain as dependent variables and time as an independent one $^{15}$. A p-value $<0.05$ was considered significant for all tests. Calculations were performed using Stata, version 8.0. 


\section{RESULTS}

\section{Devising the items}

\section{Domains selection}

The groups of patients and experts determined that a HD, which includes the presence, length and severity of pain, analgesics intake and missing workdays, would assess the main characteristics of headache episodes and their impact on work activities in patients with $\mathrm{CDH}$. The proposed items to assess pain intensity were devised to be expressed on a fivepoint visual analogue scale, once the patient has accepted to have a headache. Therefore, the four-point scale proposed by the International Classification of Headache (including 0 as no pain) was not used ${ }^{14}$.

\section{Detection of ambiguous or non-understandable items}

During the first interview $(n=10)$, two items related to length of pain were identified as non-understandable by two patients: "At what time did the headache begin? At what time did it end?" and "the pain lasted: half morning, the entire morning, half afternoon, the entire afternoon, all day?". The writing group did not find an alternative way of rephrasing these questions, so they were excluded from the internal consistency analysis. A second set of questions was applied to a new group of patients $(n=10)$. All patients understood these items.

\section{Internal consistency}

The five factors identified by the factor analysis explained $75 \%$ of rotated variance. The first factor explained $27 \%$ of variance and had high loading on "How many hours did you have the headache today?" (number of hours with headache) (0.9). The second factor accounted for $17 \%$ of variance with a high loading on "Did you have a headache today?" (yes/no) (0.8). The third one explained $12 \%$ of the variance and had a high loading on "What medications did you have to take today to improve your headache?" (the name of the medication) (0.9). The forth explained $10 \%$ of the variance and with high loadings on "Did the headache prevent you from leaving your home?" (yes/no) (0.8) and "How strong was your headache today?" (very mild/ mild/ moderate/ severe/ very severe) (0.4). The last one accounted for $8 \%$ of the variance and had a high loading on "Did the headache prevent you from going to work today?" (yes/no) (0.9).

\section{Validity}

\section{Criterion validity}

Thirty-two patients received theHD and were asked to answer it during seven consecutive days, 25 patients returned the HD and allowed telephone interviews (175 observations). Patients for this phase were mostly women (76\%), had chronic migraine
(84\%) and had a median age of 44.6 years-old (interquartile range - IQR=25-75\%: 28.9-50.6). The median of Spearman's rho through the seven days of fulfilling the HD for presence was 0.8 (IQR 25-75\%: 0.7-0.9), for severity of pain was 0.7 (IQR 25-75\%: 0.5-0.7), for analgesics intake was 0.8 (IQR 25-75\%: 0.7-0.9). The median of Kendall's tau for length of pain through the follow-up was 0.8 (IQR 25-75\%: 0.7-0.8) (Fig 1).

The sensitivity of each item, which is defined as the proportion of positive answers among the positive ones in the golden standard, varied from 82 to $95 \%$. Likewise, the specificity, which is defined as the proportion of negative answers among the negative ones in the golden standard, varied from 86 to $96 \%$ (Table 1). After adjusting each of the main covariates (age, gender, day of fulfilling the $\mathrm{HD}$, analgesic abuse, subtype of chronic headache, and recruitment site), modifications over $20 \%$ from the original estimates were not found on the bivariate models where convergence was achieved.

\section{Construct validity}

The relationship between severity of pain and analgesics intake was statistically significant for most of the days when the HD was fulfilled (OR=1.7-11). Similarly, the relationship between length of pain and analgesics intake was significant for all the days (OR=2.5-14), as it can be seen in Fig 2. A statistically significant relationship was not found between the items devised to measure headache related missing workdays and the golden standard (data not shown).

\section{Sensitivity to change}

The $\mathrm{p}$-values for the repeated measures ANOVA for time as covariate were $<0.001$, for length of pain and 0.08 , for severity of the headache episodes.

\section{DISCUSSION}

In this study we have shown that this HD is a valid and reliable instrument in Colombian patients with $\mathrm{CDH}$ and it

Table 1. Accuracy of each item from the headache dairy.

\begin{tabular}{lcc} 
Item & $\begin{array}{c}\text { Sensitivity } \\
(95 \% \mathrm{Cl})\end{array}$ & $\begin{array}{c}\text { Specificity } \\
(95 \% \mathrm{Cl})\end{array}$ \\
\hline $\begin{array}{l}\text { Did you have a headache today? } \\
\text { How many hours did you have the } \\
\text { headache today? }\end{array}$ & $95 \%(90-98)$ & $86 \%(78-94)$ \\
$\begin{array}{l}\text { What medications did you have to } \\
\text { take today to improve your headache? }\end{array}$ & $84 \%(74-91)$ & $91 \%(86-95)$ \\
How strong was your headache & $91 \%(87-94)$ \\
today (very mild/ mild/ moderate/ & $82 \%(64-100)$ & $93 \%(90-97)$ \\
severe/ very severe)? & & \\
\hline
\end{tabular}

* Generalized estimating equations of the proportion of positive answers in headache diary among positive answers in the gold standard (sensitivity), and negative answers among negative answers in gold standard (specificity). Unstructured working correlation matrix and identity link functions were used for calculations. "An exchangeable correlation matrix was used; $\mathrm{Cl}$ : confidence interval. 
A

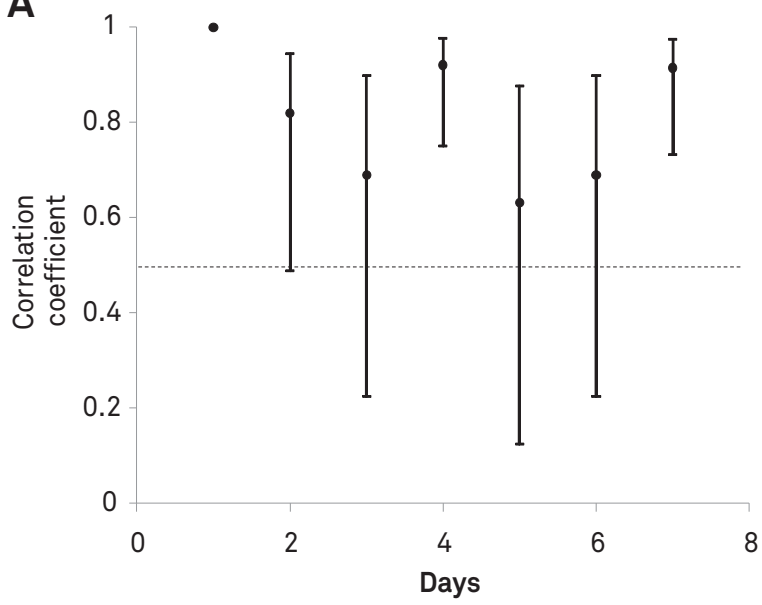

C

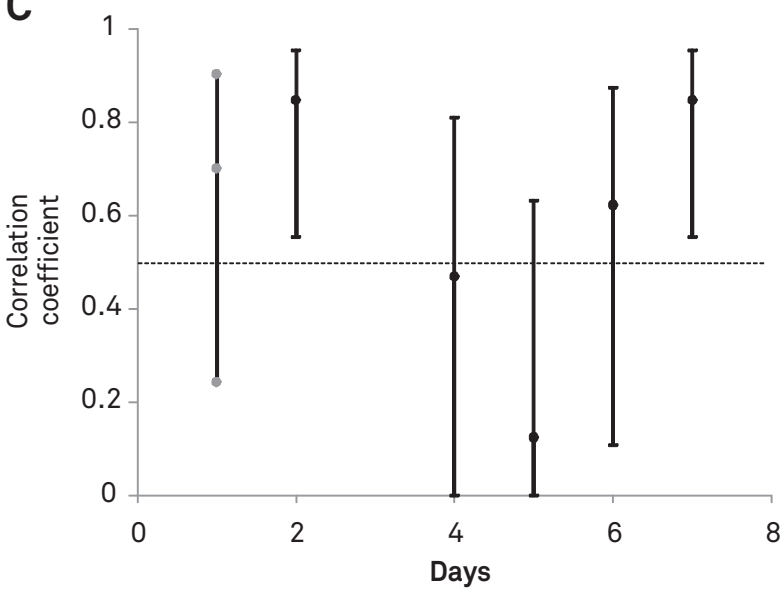

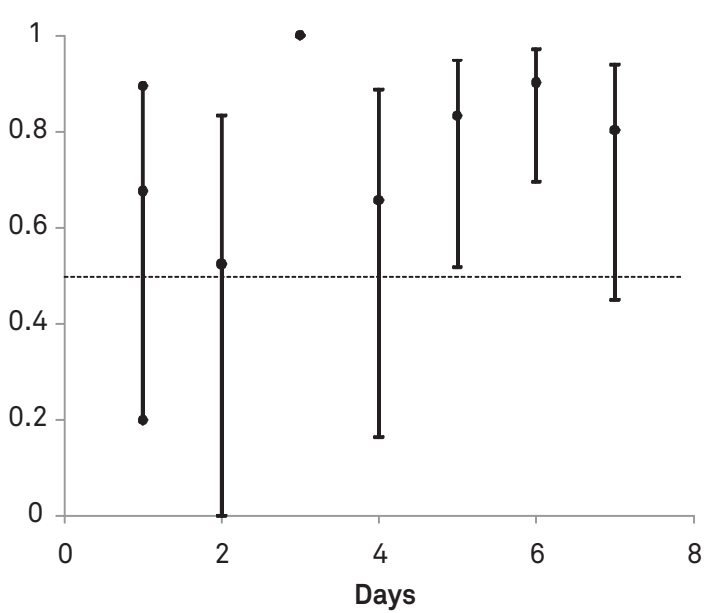

B

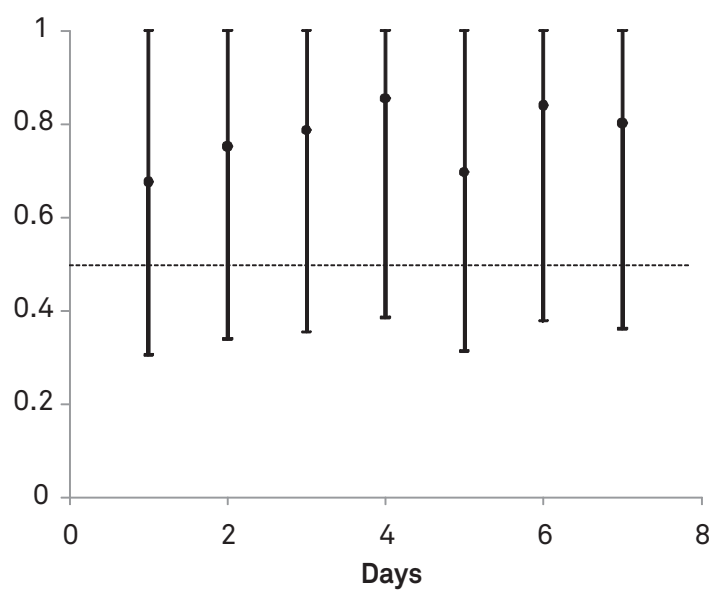

D

Fig 1. Correlations between the headache dairy and the clinical interview through the seven days of fulfilling it. A: presence; B: analgesics intake; C: severity of pain; D: length of pain.
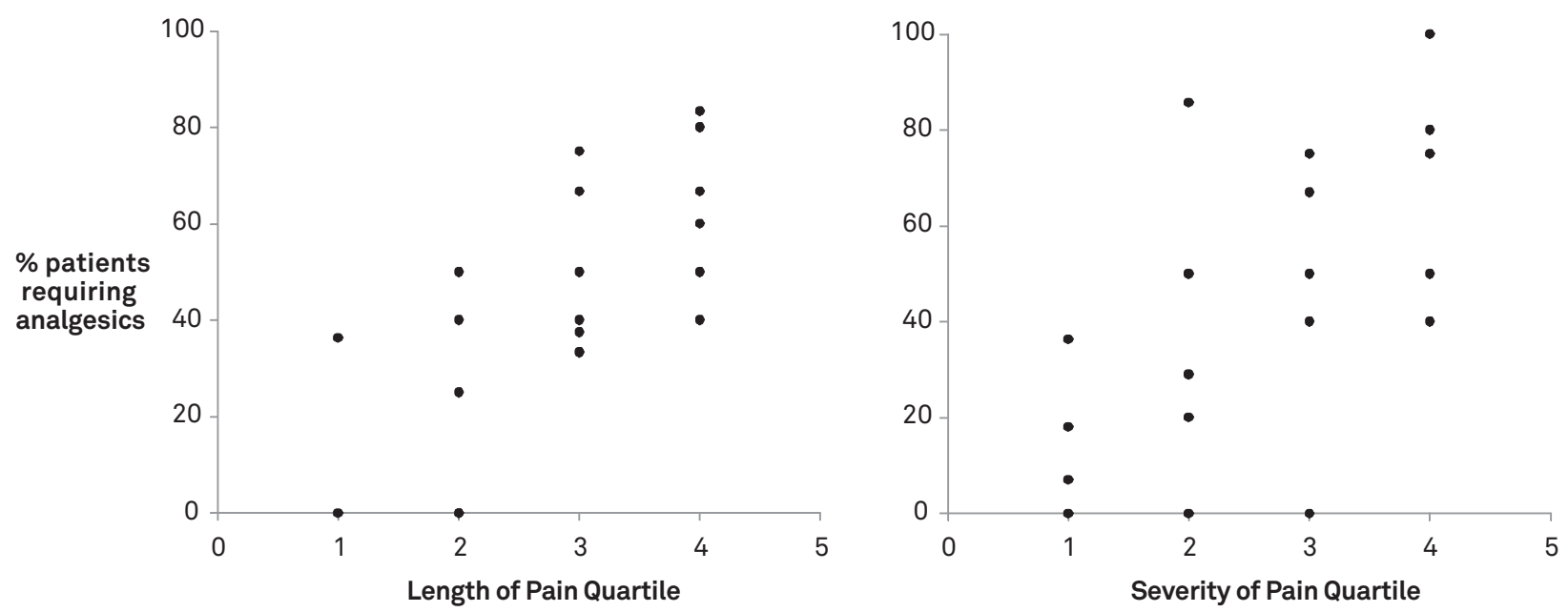

Fig 2. Relationship between length and severity of pain and analgesics intake through the seven days of fulfilling the headache diary. 
records the main characteristics of headache episodes for patients and treating physicians. The domains have been selected by a representative sample of patients and by physicians with experience in diagnosis and treatment of primary headaches (content validity). The selected items were understood by each patient. Validity has been tested through the application of the HD during seven consecutive days and the accuracy estimates have proved to be independent of age, gender, day of fulfilling and recruitment site (Fig 1 and 2).

Importantly, we believe that testing the performance of the HD longitudinally might provide more accurate estimators of accuracy and adherence ( $\approx 80 \%$ in this sample). To this end, we used an approach based on the binomial family of GEE. Previous authors have proposed GEE as a valid method to determine proportions of dichotomous variables of correlated data $^{19}$. Even thought, to the best of our knowledge, GEE has not been previously used as a method to determine accuracy estimates for single studies, since these are proportions, they provide the rationale for the use of GEE (Table 1). Likewise, a regression model based on GEE might provide a method to evaluate the effect of covariates over such estimates.

Sensitivity to change was tested using a multiple measures approach $^{15}$. Despite the short time of follow-up, a change in the headache severity and a trend to a decreased length of pain were observed in this study after the beginning of therapy or modification of previous treatment. This change, on a week to week basis, has been observed by other authors ${ }^{20}$.
There are two important issues about the validity of this HD. First, although the expert group selected impacts on work activities as a domain that should be included in the $\mathrm{HD}$, devised items did not correlate with the golden standard (data not shown). We believe that this domain is a complex construct and a single question might not account for it (from low performance to total absence). Nevertheless, we kept the item: "Did the headache prevent you from going to work today" in the final version of this HD, because of internal consistency and because it provides valuable information for research and statistical purposes.

Second, the highly variable nature of this symptom on a day to day basis prevented us to evaluate the stability of the data provided by the HD (test-retest reliability). However, the stability of the correlations through the follow-up as well as the adequate internal consistency of this instrument might account for a high reliability of the HD.

In summary, we have shown a brief HD that assesses the main characteristics of headaches. This diary includes the main domains identified by patients and treating physicians, it also has a high internal consistence and is a valid instrument in Colombian patients with $\mathrm{CDH}$. We believe that this instrument might help patients with adequate feedback of headache progress, allow treating physicians a better assessment of a goal-directed therapy and allowing them to improve the reliability of results from future researches in Colombian patients with $\mathrm{CDH}$.

\section{References}

1. Scher Al, Stewart WF, Liberman J, Lipton RB. Prevalence of frequent headache in a population sample. Headache 1998;38:497-506.

2. Bigal ME, Sheftell FD, Rapoport AM, Lipton RB, Tepper SJ. Chronic daily headache in a tertiary care population: correlation between the International Headache Society diagnostic criteria and proposed revisions of criteria for chronic daily headache. Cephalalgia 2002;22:432-438.

3. Queiroz LP, Peres MF, Kowacs F, et al. Chronic daily headache in Brazil: a nationwide population-based study. Cephalalgia 2008;28:1264-1269.

4. Queiroz LP, Peres MF,Piovesan EJ, et al.A nationwide population-based study of tension-type headache in Brazil. Headache 2009;49:71-78.

5. Guitera V, Muñoz P, Castillo J, Pascual J. Quality of life in chronic daily headache: a study in a general population. Neurology 2002;58: 1062-1065.

6. Monzon MJ, Lainez MJ. Quality of life in migraine and chronic daily headache patients. Cephalalgia 1998;18:638-643.

7. Lipton RB, Bigal ME, Steiner TJ, et al. Classification of primary headaches. Neurology 2004;63:427-435.

8. Lyngberg AC, Rasmussen BK, Jorgensen T, Jensen R. Prognosis of migraine and tension-type headache: a population-based follow-up study. Neurology 2005;65:580-585.

9. Stewart WF, Lipton RB, Simon D, Von Korlf M, Liberman J. Reliability of an illness severity measure for headache in a population sample of migraine sufferers. Cephalalgia 1998;18:44-51.

10. Martin BC, Pathak DS, Sharfman MI, et al. Validity and reliability of the migraine-specific quality of life questionnaire (MSQ Version 2.1). Headache 2000;40:204-215.
11. Cramer JA, Silberstein SD, Winner P. Development and validation of the Headache Needs Assessment (HANA) survey. Headache 2001;41: 402-409.

12. Kosinski M, Bayliss MS, Bjorner JB, et al. A six-item short-form survey for measuring headache impact: the HIT-6. Qual Life Res 2003;12: 963-974.

13. WagnerTH, PatrickDL, Galer BS, Berzon RA.A new instrument to assess the long-term quality of life effects from migraine: development and psychometric testing of the MSQOL. Headache 1996;36:484-492.

14. The International Classification of Headache Disorders: 2nd edition. Cephalalgia 2004;24(Suppl 1):S9-S160.

15. Streiner DL, Norman GR. Health measurement scales: a practical guide to their development and use. 2nd ed. Oxford; New York: Oxford University Press; 1995.

16. Norman GR, Streiner DL. Biostatistics: the bare essentials. St. Louis: Mosby; 1994.

17. Altman DG, Gardner MJ.Statistics in Medicine:Calculating confidence intervals for regression and correlation. BMJ 1988;296:1238-1242.

18. Siegel S, Castellan NJ. Nonparametric statistics for the behavioral sciences. 2nd ed. New York: McGraw-Hill; 1988.

19. Hanley JA, Negassa A, Edwardes MD, Forrester JE. Statistical analysis of correlated data using generalized estimating equations: an orientation. Am J Epidemiol 2003;157:364-375.

20. Jackson JL, Shimeall W, Sessums L, et al. Tricyclic antidepressants and headaches: systematic review and meta-analysis. BMJ 2010;341:c5222. 